\title{
Estas palavras e o Shemá
}

\author{
These words and the Shemah
}

ILDO PERONDI ${ }^{a}$

\section{Resumo}

No livro do Deuteronômio, a expressão "estas palavras" é repetida várias vezes pelo redator final com o objetivo de introduzir os discursos que Moisés profere ao povo antes da sua morte e antes de o povo entrar na terra. As palavras de Moisés concluem o Pentateuco e, por conseguinte, toda a Torá que norteará a vida do povo de Israel. Dentre estas palavras, encontra-se também o Shemá, a oração por excelência que constitui a profissão de fé israelita, também o ponto central na tradição e na espiritualidade hebraica. Este artigo visa analisar a importância e o significado que estas palavras e o Shemá tiveram - e continuam a ter - para o povo judeu, bem como para o cristianismo.

Palavras-chave: Deuteronômio. Palabras. Torá. Shemá.

\section{Abstract}

In the book of Deuteronomy the words "these words" are repeated several times by the final redactor in order to introduce the discourses that Moses uttered to the people before his death and before the people entered the earth. The words of Moses conclude the Pentateuch and, therefore, all the Torah that will guide the life of the people of Israel. Among these words is also the Shemá, the prayer par excellence, which constitutes the profession of Israelite faith and also the center point in Hebrew tradition and spirituality. The article seeks to analyze the importance and meaning that these words and the Shemá have had and continue to have for the Jewish people and also for Christianity.

Keywords: Deuteronomy. Words. Torah. Shemá.

\footnotetext{
a Pontifícia Universidade Católica do Paraná (PUCPR), Curitiba, PR, Brasil. Doutor em Teologia Bíblica, e-mail: ildo.perondi@pucpr.br
} 


\section{Introdução}

O quinto livro do Pentateuco na Bíblia Hebraica tem como nome Debarîm (Palavras) que traduz com mais exatidão o conteúdo de todo o livro. Este título é tirado de uma palavra do primeiro versículo: "Estas são as palavras que Moisés dirigiu a todo Israel do outro lado do Jordão [...]"1. No entanto, nas traduções para a Língua Portuguesa, o livro recebeu o nome de Deuteronômio por causa da afirmação de Dt 17,18: “Quando subir ao trono real, ele deverá escrever num livro, para seu uso, uma cópia desta Lei, ditada pelos sacerdotes levitas". Quando em Alexandria se fez a tradução grega, chamada Setenta ou Septuaginta, a expressão "cópia desta Lei" foi traduzida por "to deuteronomion touto" ( = esta segunda Lei) e no latim manteve "deuteronomium" e daí em diante o termo se fixou nas demais traduções. Mesmo assim, o título é inadequado. Somente uma parte do Livro refere-se a leis, que são uma retomada do Código da Aliança de Ex 20-23.

\section{“Estas palavras"}

O livro do Deuteronômio traz "as palavras" de Moisés como sua despedida do povo, conduzido por ele desde o Egito até Moab, de onde já se pode contemplar a terra prometida. O Deuteronômio apresenta os quatro grandes discursos de Moisés. É o testamento espiritual que Moisés deixa ao povo antes que este entre na terra e antes da sua morte no monte Nebo. Os discursos são dirigidos à segunda geração, isto é, aquela que não teve acesso aos eventos do Sinai (ou Horeb). Assim Moisés interpreta a Torá sinaítica e também o Decálogo fornecendo "a chave hermenêutico-legal para construir a relação entre a Torá sinaítica e a Torá de Moab” (OTTO, 2011, p. 86).

Moisés exorta o povo à fidelidade e explica quais são as condições da vida futura depois da tomada de posse da terra. Embora o livro contenha uma série de leis e códigos, "é o Deuteronômio que consistentemente fala, pela

\footnotetext{
1 Os textos bíblicos são da tradução da Bíblia de Jerusalém (2004), com alguma alteração quando necessário. Para o Tetragrama, com o Nome divino sempre que possível, mantém-se YHWH ou, eventualmente, usa-se Senhor.
} 
primeira vez, não de leis, mas da Lei, a Torá" (BLENKINSOPP, 2007, p. 224). A sua grandeza reside na força pedagógica exercida pelo líder que conduziu o povo pelo deserto e está prestes a se despedir. Neste sentido, o livro do Deuteronômio adquire grande importância, pois oferece a chave de interpretação para compreender toda a Lei de Moisés, isto é, o inteiro Pentateuco como Escritura Sagrada para Israel. Por meio dos discursos e das suas palavras, Moisés é retratado como aquele que explica a vontade Deus a uma geração que não participou dos eventos passados, torna-se um comentário que permite às gerações futuras compreender como aproximar-se da Lei e entendê-la na sua função de guia e como as tradições do passado consentem de viver a atualidade da aliança com o Senhor (PAPOLA, 2011, p. 10).

Moisés interpreta o Decálogo, as “dez palavras” (Dt 4,13; 10,4; cf. Ex 34,28). Esta geração que recebe as palavras de Moisés não ouviu a revelação do Sinai. Depois, Moisés se despede do povo, antes de morrer, pois é esta geração que irá entrar e tomar posse da terra prometida. Segundo E. Otto: "O povo da geração do êxodo não podia estar em condições de entender na Montanha de Deus no deserto do Sinai a revelação divina do Decálogo, e o povo da segunda geração podia tomar conhecimento de toda a Torá sinaítica somente sob a forma da interpretação mosaica" (2011, p. 90).

Os discursos são proferidos por Moisés durante um único dia. É evidente que estes dicursos foram atribuídos a Moisés, no entanto, eles fazem parte de um longo processo redacional que durou vários séculos (PAGANINI, 2011, p. 17). Vale pontuar que não é pretensão deste artigo analisar o processo redacional e literário dos discursos e de todo o livro.

A sequência destes discursos fazem a divisão do Livro e são assinaladas pelo mesmo pronome demonstrativo ‘elleh “estas” $(1,1 ; 12,1 ; 28,69 ; 31,1)$ ou zo't “esta" (4,44, 33,1). Assim, o narrador, em breves palavras, prepara a palavra que Moisés vai proferir ao povo, embora o pronome não apareça somente no início dos quatro discursos, como se vê a seguir:

- "Estas são as palavras que Moisés dirigiu a todo Israel do outro lado do Jordão [...]" (Dt 1,1). É o primeiro discurso de Moisés $(1,6-4,40)$ no qual é recapitulada a história do povo de Deus desde a saída da escravidão até a chegada em Fasga, onde já se pode avistar a terra prometida. As palavras que 
Moisés dirige ao povo ressaltam a providência divina que cuidou e protegeu o povo, destaca a importância de Israel ser o povo eleito e, sobretudo, o dom da terra prometida por Deus.

- "Esta é a Lei que Moisés promulgou para os israelitas..." (Dt 4,44). Depois de uma breve introdução (4,44-49), inicia-se o segundo discurso de Moisés (5,1-11,32, em que Moisés apresenta o Decálogo e uma série de instruções que preparam o terceiro discurso. É possível que o segundo discurso tenha existido separadamente do livro. Seria um texto catequético e cultural.

- "São estas as disposições e normas que cuidareis de pôr em prática na terra cuja posse YHWH, Deus de teus pais, te dará..." (Dt 12,1). Este longo discurso $(12,2-28,68)$ contém o chamado Código Deuteronômico (12-26), com leis de diversas origens e temas diversos. Muitas destas leis podem ter vindo do Reino do norte, sobretudo depois da queda da Samaria, e representam o livro da Lei encontrado por Josias no Templo (2Rs 22,8-10).

- "São estas as palavras da Aliança que YHWH mandara Moisés concluir com os israelitas na terra do Moab" (Dt 28,69). O discurso vai até o capítulo 32, versículo 20. Não é uma nova aliança, mas completa a aliança do Sinai. O objetivo deste discurso é reforçar o espírito de fidelidade e de obediência à Lei que já foi promulgada e já é de conhecimento do povo.

- "Moisés falou estas palavras a todo o Israel" (31,1). Moisés anuncia o seu sucessor (Josué) e dá as últimas instruções ao povo. Em estilo poético, Moisés proclama o chamado Cântico de Moisés (32,1-43). Inserido neste contexto, o poema torna-se uma chave para compreender a história da relação entre YHWH e Israel. Então Moisés prepara o povo para a sua morte. As últimas palavras de Moisés são introduzidas desta forma pelo narrador: "Quando Moisés terminou de pronunciar estas palavras a todo o Israel" $(32,45)$. Assim, a comunicação da Torá iniciada em 5,1 chega ao fim no momento em que Moisés coloca a Torá no centro da vida do povo (PAPOLA, 2011, p. 371).

- "Esta é a bênção com que Moisés, homem de Deus, abençoou os israelitas, antes de morrer" $(33,1)$. Em forma de poema, Moisés abençoa as tribos da mesma forma como Jacó fez antes de morrer ( $G$ n 49) e prediz o futuro e o destino das doze tribos. Em seguida, o narrador relata com breves palavras a morte de Moisés. 
No Livro do Êxodo, o próprio Deus era quem falava a Moisés e este retransmitia ao povo as palavras recebidas: "Deus pronunciou todas estas palavras, dizendo [...]" (Ex 20,1). Já no Livro do Deuteronômio são as palavras de Moisés que se tornam a Palavra de Deus. Portanto, Moisés age como um mestre $(1,5 ; 4,5 ; 5,31 ; 6,1)$, que aponta para a origem da instrução legal do Deuteronômio no ofício de ensinador sacerdote-levita (BLENKINSOPP, 2007, p. 229).

Embora a tradição judaica afirme que Moisés seja o autor do Deuteronômio, a crítica moderna identifica este Livro como o início da Obra Histórica Deuteronomista (OHD), que fará a redação também dos livros de Josué até 2Reis. No Deuteronômio, praticamente não há o problema da complexidade das Fontes do Pentateuco (Javista, Eloísta, Sacerdotal e Deuteronomista), pois quase todo o Livro é atribuído a uma única fonte (D), com poucas exceções a partir do capítulo 31. A escola Deuteronomista é proveniente dos levitas que se transferiram para Jerusalém depois da destruição do Reino do Norte (721 a.C.) e defensores do sistema tribal. Estes colocaram na boca de Moisés suas teorias para conferir-lhe credibilidade, continuidade e autoridade. Talvez sua estrutura primeira seja do livro encontrado em 622 (cf. 2Rs 22,8-11), o qual deu base a Josias para o início da reforma do culto.

Portanto, não se deve pensar num único autor para o livro, e sim de grupos de diferentes fontes que "demonstram a diversidade de contribuições e influências que estão presentes no Deuteronômio conforme se encontra atualmente em nossas Bíblias" (KRAMER, 2006, p. 16).

O Livro é antes de tudo uma advertência a Israel, por meio das palavras de Moisés, que é o personagem central de todo o Livro, são recordadas ao povo algumas mensagens importantes:

a) O povo está entrando para tomar posse da Terra que YHWH, em juramento, prometeu aos pais;

b) o povo deve procurar o $\mathrm{YHWH}$, seu Deus, e ter respeito pelo seu Nome;

c) o povo deve conhecer e seguir as Leis, normas e mandamentos recebidos de Deus para ter a vida, a felicidade e a bênção; 
d) o povo deve ser fiel e servir a $\mathrm{YHWH}$, o Deus que os libertou da escravidão do Egito. Antes eram 'avadim (escravos) do faraó, agora são 'avadim (servos) de $\mathrm{YHWH}$;

e) o povo torna-se um povo livre e agora deve ser capaz de escolher o projeto de vida oferecido por Deus.

Quando tomar posse da terra, deverá ter em mente alguns princípios que nortearão a sua sobrevivência: seguir a Lei (Torá), servir ao Senhor, evitar outros deuses (idolatria). Este é o único modo para poder sobreviver na nova Terra. Parece que todo o Livro encaminha para Dt 30,15-20: escolher entre a vida e a morte; a felicidade e a infelicidade; a bênção e a maldição. Isso significa uma relação harmoniosa com o Deus que os libertou da escravidão, mas também uma relação fraterna entre irmãos, por isso o Código da Aliança e as leis que são ordenadas visam ao equilíbrio social e à "proteção dos grupos econômica e juridicamente mais fracos na sociedade" (CRÜZEMANN, 2002, p. 498).

A morte de Moisés antes de entrar na terra prometida aparece quase que injusta, haja vista que ele foi o líder e enfrentou tantas dificuldades tanto para a saída do Egito quanto para a realização da longa caminhada pelo deserto, enfrentando problemas externos ou causados pelo próprio povo. No entanto, a morte do líder contemplando a terra ensina que a promessa é mais importante que a posse. Será a fidelidade às promessas e à aliança que garantirão a continuidade do povo de Deus. A terra pode ser perdida; a monarquia pode desaparecer. Mas a promessa e a Torá continuarão vivas. Dessa forma, o Deuteronômio serve como elo entre a Lei e os Profetas; entre o êxodo e o ingresso na terra (PAPOLA, 2011, p. 11).

\section{Torá, a Lei de Moisés}

A Lei que foi prescrita por Moisés (Dt 33,4) torna-se a Halaká, mais do que um conjunto de leis a serem cumpridas, a Torá indica o caminho que o judeu deve seguir (Salmos 1 e 119). São os ensinamentos que os pais devem transmitir aos filhos nos caminhos da vida e ao mesmo tempo adverti-los contra as ciladas da morte. São instruções, orientações e normas que ajudam o povo a viver bem. Crüzemann (2018, p. 12) observa que: 
No Deuteronômio Torá transforma-se no conceito mais importante da vontade de Deus universal e literariamente fixada (p. ex. Dt 4,44s. 30,10; 31,9). Aqui Torá abrange tanto narrações (esp. Dt 1,5) quanto leis (cf. esp. SI 78,1.5.10). Mais tarde, esse conceito deuteronômico designa a lei de Esdras (p. ex. Ne 8,1), todo o Pentateuco, mas também a palavra profético-escatológica de Deus para os povos (Is 2,3 par. Mq 4,2 ; Is 42,4).

Por duas vezes, o texto menciona "as dez palavras" (Dt 4,13; 10,4), referindo-se ao Decálogo. Nota-se que, para a tradição judaica, todas as mitsvôt (preceitos) da Torá totalizam 613 mandamentos que não se encontram somente no Deuteronômio, mas nos cinco primeiros livros da Bíblia. A soma de $6+1+3$ é 10, portanto, nas Dez Palavras estaria resumida toda a Torá. Destes preceitos, 365 são negativos e correspondem aos dias do ano solar, indicam as coisas que os judeus são proibidos de fazer; 248 são positivos, correspondendo ao número de órgãos do corpo e relacionam-se às coisas que os judeus são obrigados a fazer (BUNIM, 1998, p. 8-9).

Os 613 mandamentos são frutos de uma composição com propósitos homiléticos "para ensinar que cada dia tem suas tentações e cada parte do corpo tem sua função sagrada" (SELTZER, 1990, p. 275). Uma lista completa dos 613 mandamentos foi elaborada por Ephraïm (1998, p. 208-236). Segundo o Talmud Bavli, tratado Nezikim, 24a, a palavra "Torá" tem como valor numérico 611. Os dois mandamentos, "Eu sou YHWH, teu Deus" (Dt 5,6) e "Não terás outros deuses diante de mim" (Dt 5,7), foram transmitidos pela boca do próprio Deus Todo Poderoso e, assim, a Torá completa o número 613 (MEYER, 2012, p. 11).

Os mandamentos (não só os dez, mas toda a Torá) devem ser compreendidos como positivos e reveladores, são prescrições de vida e de liberdade, fora das quais germinam a falta de sentido e a morte (DI SANTE, 2004, p. 73). No entanto, o judeu de hoje está impedido de poder praticar todos os mandamentos, tendo em vista que muitos deles dependem da existência do Templo, destruído no ano 70 d.C. Para o judeu, as mitzvôt não constituem um fardo pesado e sim uma alegria, por isso, devem ser cumpridas sem esperar recompensa, ainda que esta exista (BUNIM, 1998, p. 9).

O cumprimento literal de todos os preceitos torna-se um problema para o judaísmo. Alguns mandamentos sugerem a eliminação de quem fere o bom 
comportamento na comunidade, com sentenças, a exemplo, a pena de morte. No entanto, as expressões não podem ser tomadas ao pé da letra. As transgressões deviam ser julgadas pelos tribunais (mais tarde sinédrios), compostos de pelo menos vinte e três juízes; em casos especiais, este número podia ser aumentado para até setenta e um membros. Os juízes invocavam muitos argumentos e consideravam várias circunstâncias atenuantes para salvar a vida da pessoa que devia enfrentar uma sentença de morte. "Um tribunal rabínico que mandou executar uma única pessoa em setenta considerado um 'tribunal maldito'” (BUNIM, 1998, p. 3). Para assegurar a justiça nos julgamentos, a Lei exigia o depoimento de pelo menos duas testemunhas (Dt 19,15) que tinham realmente presenciado o crime para que uma pessoa suspeita fosse condenada e assim evitar que evidências circunstanciais condenassem um inocente (BUNIM, 1998, p. 65).

Até que ponto alguns destes preceitos podem ser transgredidos em casos extremos? A interpretação judaica, baseada no Talmud, procura manter “certa distância" entre a Palavra de Deus e a compreensão humana resultante das Sagradas Escrituras quando se trata de salvaguardar a vida, pois a primazia à defesa da vida se impõe à prática religiosa: transgredir as leis para preservar a vida. É certo que isso exige ter uma hierarquia de valores em que transgredir seja “exceção da exceção” (MEYER, 2012, p. 12-13).

A tradição judaica ensina também que, segundo o primeiro relato da Criação (Gn 1,1-2,4a), o cosmos foi criado pelo poder da palavra de Deus. Neste relato é repetida por dez vezes a expressão wayyomer Elohim ("E Deus disse"), (Gn 1,3.6.9.11.14.20.24.26.28.29 - segundo o texto hebraico). Desta forma, a palavra de Deus tem o poder criador. Ao mesmo tempo, a Torá contém as “dez palavras" que é o resumo dos 613 preceitos (Decálogo). Portanto, com dez palavras Deus criou o mundo e com dez palavras Ele sustenta o mundo.

A Torá, ao longo da história, faz parte da vida do povo judeu. É ela que faz o povo viver. Um judeu autêntico não pode separar-se da Torá porque ela é a sua vida. Os sábios de Israel ensinam que "A Torá é nosso fôlego, nossas batidas cardíacas, o próprio espírito de vida do povo judeu" (BUNIM, 1998, p. 98).

Com a destruição do Templo em 70 d. C., além da cidade de Jerusalém, os judeus perderam o lugar mais importante para suas celebrações litúrgicas e 
ofertas de holocaustos e sacrifícios. O judaísmo ficou na dependência exclusiva da Torá e dos seus estudiosos: "A Torá tornou-se, de fato, o Templo portátil de Israel. Ela sozinha poderia assegurar a sobrevivência do povo judeu" (BUNIM, 1998, p. 98).

\section{O Shemá Yisrael}

É no livro do Deuteronômio $(6,4)$ que se encontra a oração por excelência, que constitui a profissão de fé israelita, é o ponto central na tradição e na espiritualidade hebraica:

Shemá Yisrael YHWH Elohênu, YHWH 'ehad!

("Escuta, Israel, YHWH nosso Deus é o único YHWH!").

O versículo apresenta certa dificuldade de tradução, sobretudo da segunda parte (PAGANINI, 2011, p. 188; MAYES, 1987 p. 176). A opção de tradução escolhida é preferível baseada em G. Papola (2011, p. 113), ele sugere que o Deuteronômio utiliza sempre 'elohenu (nosso Deus), como aposição de YHWH, criando desta forma uma fórmula fixa ("YHWH nosso Deus").

Esta oração e profissão de fé se tornou "a fórmula oracional que é até hoje a mais importante do judaísmo" (OTTO, 2011, p. 91). Segundo Kraemer, o Shemá "certamente abria o código legal deuteronômico no seu estágio original” (2006, p. 7). É a expressão mais célebre da tradição religiosa do povo judeu e ao mesmo tempo uma síntese da sua teologia e espiritualidade.

O verbo no imperativo "Escuta Israel”, além de constar no capítulo 6, versículo 4, aparece outras vezes no livro (em 5,1; 9,1; 20,3; 27,9). É um chamado enfático que remete à tradição sapiencial $(\operatorname{Pr} 1,8)$ na qual o pai educa o filho a desenvolver a atenção e ser obediente diante da instrução que recebe, pois esta conduz à vida. Assim, por meio das instruções de Moisés, o povo é chamado a escutar e reconhecer o Deus que fala e transmite suas instruções para que este possa viver e ser fiel à Aliança firmada no Sinai. Assim, o Shemá introduz o mandamento do amor somente a YHWH. Não é uma afirmação do monoteísmo, mas de exclusiva devoção a YHWH que é o tema dominante em todo o livro (BLENKINSOPP, 2007, p. 232). 
A afirmação de que YHWH é o único Deus de Israel assegura a unicidade de Deus sem, no entanto, negar a existência da divindade dos outros povos, somente acentua a particularidade da relação de comunhão que se estabeleceu mediante o pacto de aliança firmado entre $\mathrm{YHWH}$ e Israel (PAGANINI, 2011, p. 188). A expressão é uma das formulações mais sugestivas da fé de Israel, mesmo que em todo o Deuteronômio só esteja presente nesta passagem.

A unicidade de YHWH deve ser considerada de vários pontos de vista. É uma oposição de YHWH à multiplicidade dos outros deuses (Dt 5,7; 6,14). É uma afirmação não tanto do monoteísmo, mas do modo de conceber YHWH que possui um só nome, que não tem nenhuma imagem e, sobretudo, é a origem única de Israel. Assim, a unicidade de YHWH exprime o fato de que Ele não possui comparação com as outras divindades, como Moisés já havia mencionado várias vezes (Dt 4,7.34.35.36) (PAPOLA, 2011, p. 114-115).

Todo israelita deve recitar o Shemá todos os dias, pela manhã e à noite. As primeiras palavras que a criança deve aprender a pronunciar são: Shemá Yisrael (Escuta Israel!) (MAYES, 1981, p. 176). E as últimas palavras que o israelita pronuncia ao morrer são: Hashem Elohênu, Hashem 'echad ("O Eterno é nosso Deus, o Eterno é um”). Estas palavras não são dirigidas ao ouvido, mas ao coração, buscando penetrar o interior e atingir a sensibilidade, isto é, a alma de quem as escuta (TORÁ, 2001, p. 524-525).

Além deste versículo introdutório, a oração do Shemá é constituída de outros três textos da Torá. Estas três partes formam uma unidade estrutural e apresentam-se como uma oração unitária, de modo que as partes que a compõem não são justapostas, mas obedecem a uma dinâmica de harmonia e coerência.

O primeiro texto é Dt 6,5-9, que vem logo em seguida ao Shemá Yisrael $(6,4)$, contém uma série de imperativos, com os quais $\mathrm{YHWH}$ se dirige ao seu povo ligando-o à sua vontade, tem como objetivo recordar o amor ao Senhor e também que estas palavras estejam presentes em toda a vida do israelita:

Portanto, amarás o YHWH teu Deus com todo o teu coração, com toda a tua alma e com toda tua força. Que estas palavras que hoje te ordeno estejam em teu coração! Tu as inculcarás aos teus filhos, e delas falarás sentado em tua casa e andando em teu caminho, deitado e de pé. Tu as atarás também à tua mão como um sinal, e serão 
como um frontal entre os teus olhos, tu as escreverás nos umbrais da tua casa, e nas tuas portas.

É deste trecho da Torá que provém o costume do israelita ter a mezuzah (significa "umbral"), um recipiente retangular pequeno afixado ao lado direito no batente da porta, contendo no seu interior um texto da Torá (preferencialmente Dt 6,4) assinalando que se trata de uma casa judaica, na qual moram pessoas seguidoras da Torá. Deriva daqui também o uso dos filactérios (tefillin, remanescente de tefillá = prece) que são as pequenas caixas de couro amarradas ao braço ou à testa atadas ao corpo por correias, com textos da Torá no seu interior) e também o uso de tsitsit (franjas ligadas às vestes), que ficam visíveis para lembrar as mitzvot, os preceitos a serem praticados.

O segundo trecho a ser recitado é Dt 11,18-21, que em parte se assemelha ao primeiro texto:

Colocai estas minhas palavras no vosso coração e na vossa alma, ataia-as como um sinal em vossa mão, e sejam como um frontal entre os vossos olhos. Ensinai-as aos vossos filhos, falando delas sentado em tua casa e andando em teu caminho, deitado e de pé; tu as escreverás nos umbrais da tua casa, e nas tuas portas, para que vossos dias e os dias de vossos filhos se multipliquem sobre a terra que YHWH jurou dar aos vossos pais, e sejam tão numerosos como os dias em que o céu permanecer sobre a terra.

As palavras da Torá devem envolver todo o ser e todo o espaço do israelita, devem ser ensinadas aos filhos e às gerações seguintes. A fidelidade à Torá garantirá a posteridade na terra que o Senhor prometeu aos pais.

O terceiro texto do Shemá Yisrael não é do Deuteronômio, é tirado do Livro dos Números (15,37-41) e narra um momento em que o povo está na caminhada pelo deserto, quando Moisés transmite aos filhos de Israel as orientações recebidas de YHWH:

YHWH falou a Moisés e disse: "Fala aos filhos de Israel: tu lhes dirás, para as suas gerações, que façam borlas nas pontas das suas vestes e ponham um fio de púrpura violeta na borla da ponta. Trareis, portanto, uma borla, e vendo-a vos lembrareis de todos os mandamentos de $\mathrm{YHWH}$. E os poreis em prática, sem jamais seguir os desejos do vosso coração e dos vossos olhos, que vos têm levado a vos prostituir. Assim vós vos lembrareis de todos os meus mandamentos e os poreis em prática e sereis consagrados ao vosso Deus. Eu sou YHWH vosso Deus, que vos tirei da terra do Egito, a fim de ser vosso Deus, eu, YHWH vosso Deus". 
Desta passagem vem o costume de vestir o tallit, uma mantilha em forma de escapulário que os judeus praticantes usam. As borlas com um fio de púrpura eram um sinal importante nas vestes cultuais (Ex 25,4; 26,11; 28,1) e tinham o objetivo de chamar a atenção para o caráter sagrado da comunidade. Novamente o texto insiste na recordação de que a Torá deve ser transmitida e recordada diariamente.

O mais importante dos três textos é o primeiro, pois o segundo e o terceiro podem ser omitidos ou abreviados (DI SANTE, 2004, p. 71). Em certas regiões é costume que, depois do segundo texto, seja recitada mais uma passagem da Torá (Dt 11,13-21) que inclui as bênçãos sobre as lavouras e os animais:

\begin{abstract}
Portanto, se de fato obedecerdes aos mandamentos que hoje vos ordeno, amando a YHWH vosso Deus e servindo-o com todo o vosso coração e com toda a vossa alma, darei chuva para a vossa terra no tempo certo: chuvas de outono e de primavera. Poderás assim recolher teu trigo, teu vinho novo e teu óleo; darei erva no campo para o teu rebanho, de modo que poderás comer e ficar saciado. Contudo, ficai atentos a vós mesmos, para que o vosso coração não se deixe seduzir e não vos desvieis para servir a outros deuses, prostrando-vos diante deles. A cólera de YHWH se inflamaria contra vós e ele bloquearia o céu: não haveria mais chuva e a terra não daria o seu produto; deste modo desapareceríeis rapidamente da boa terra que YHWH vos dá!
\end{abstract}

Mesmo que estas palavras sejam pronunciadas por Moisés, em determinado momento, YHWH assume diretamente o discurso: "darei...". Dessa forma, Deus se compromete pessoalmente em garantir a fecundidade da terra, cumprindo assim as promessas $(28,20 ; 29,4)$ e garantindo que continuará presente junto ao povo mesmo depois da entrada na terra.

Quando os judeus recitam o Shemá, a última palavra 'ehad tem um significado especial. A primeira letra (alef) tem o valor numérico de um, diz respeito ao Deus Único; a segunda (het) tem valor de oito, significa que YHWH tem a soberania absoluta sobre os sete Céus e a Terra; a terceira (dalet), com o valor de quatro, lembra que Ele também domina os quatro pontos cardeais (a totalidade). Mais ainda: a soma das três consoantes é treze! Ora, treze são os atributos de Deus, revelados a Moisés quando desceu do Sinai com as tábuas da Lei (Ex 34,6-7). E o tetragrama YHWH com o nome de Deus somado possui o valor de vinte e seis $(10+5+6+5=26)$, que é dobro de treze! (ZUMERKORN, 2005, p. 65; TORÁ, 2001, p. 524-525). 
O Shemá tornou-se também a invocação feita pelos judeus ao passarem por perseguições e mesmo a morte, recitando-o com fervor, não com um sentimento rancoroso, mas somente com alegria da dedicação. Conta a história que Rabi Akiva foi preso por ocasião da revolta de Bar Kochba (135 d. C.). Ao ser torturado pelos romanos, os sofrimentos eram insuportáveis, sentiu que chegara a hora da sua morte. Akiva elevou os olhos ao céu e com todas as forças que lhe restavam exclamou: "Ouve, ó Israel, o Senhor nosso Deus, o Senhor é Um!". E quando ele chegou à palavra "Um" ele se apegou firmemente a ela e continuou a repeti-la com carinho, recusando-se a calar-se, e morreu com ela nos lábios (AUSUBEL, 1989, p. 783; DI SANTE, 2004, p. 70-71).

A recitação do Shemá dá ao judeu a imagem de um Deus que está sempre ao lado do seu povo "para a vida e para a paz": de dia e de noite, na opressão e na liberdade (DI SANTE, 2004, p. 93).

\section{As palavras do Deuteronômio e o Novo Testamento}

Para o Novo Testamento, o Deuteronômio será muito importante, pois é um dos livros do Antigo Testamento mais citados, ao lado de Salmos e do livro do Profeta Isaías. Trata-se do Livro que influencia a teologia do Apóstolo Paulo e as primeiras comunidades cristãs. É do Deuteronômio que nos chega também a ideia de Deus como um Pai amoroso e misericordioso (Dt 4,31; 32, 10-11).

Também é do Deuteronômio a fonte de onde Jesus tira o maior dos mandamentos ao responder ao escriba que se aproximou para experimentálo: “Amarás o Senhor teu Deus com todo o teu coração, com toda a tua alma e com todo o teu ser" (LC 10,27; Mt 22,36-38; cf. Dt 6,5) ligando-o com a necessidade do amor ao próximo (Lv 19,18), isto é, a prática da compaixão em relação aos necessitados (LC 10,28-37). E ainda é o Deuteronômio que fundamenta a escolha entre os dois caminhos (Mt 7,13-14; cf. Dt 30,15-20) e a solidariedade para com os órfãos, viúvas e estrangeiros, a tríade social que aparece onze vezes em todo o Deuteronômio e são as categorias sociais que mais recebem a atenção da parte de $\operatorname{Deus}^{2}$ (FRIZZO, 2011).

\footnotetext{
2 FRIZZO, A. C., Uma tríade social que qualifica o ato de conhecer a Deus, p. 15-42. O artigo é um resumo da sua tese doutoral em que aborda com mais profundidade o tema.
} 
O Evangelho de Mateus guarda muitas semelhanças com o Livro do Deuteronômio. O livro é dividido em cinco partes (como a Torá) com uma introdução e uma conclusão que lhe fazem de moldura. Jesus reafirma a validade da Lei (Mt 5,17-20); porém, faz uma nova interpretação do Decálogo e, sobretudo, dos preceitos éticos e da justiça. Além disso, Jesus ressalta a importância do amor a Deus e ao próximo. Mateus apresenta Jesus como um novo Moisés que ensina o povo e atualiza a Torá.

Outra característica que assemelha o Evangelho de Mateus ao Deuteronômio são as palavras pronunciadas por Jesus. Ao final ou início de cada um dos cinco livrinhos, Mateus indica que foram "essas palavras" de Jesus $(7,28 ; 11,1 ; 13,53 ; 19,1 ; 26,1)$. São discursos, instruções, parábolas ou ensinamentos que Jesus dirige, como um Mestre, às multidões ou aos seus discípulos. Desta forma, Mateus indica que Jesus está fazendo uma ligação com o Deuteronômio, que começa com "essas palavras" que Moisés dirigiu a todo Israel.

Quanto à validade da Torá para os cristãos, Crüzemann aponta que é preciso separar "o que ainda vale do que não tem mais validade" (2018, p. 497). Existe uma distância histórica entre a Torá e o Evangelho e também uma alteração da realidade social e geográfica em que o cristianismo floresceu, as quais exigem sempre novas hermenêuticas criativas, atualizadas aos diversos contextos, a fim de evitar um fundamentalismo cego que impeça que a defesa da vida prevaleça sobre a letra da lei.

\section{Considerações Finais}

“Estas palavras" proferidas por Moisés no livro do Deuteronômio tornam-se as palavras finais da Torá. É por meio das palavras de Moisés que YHWH revela a sua Palavra, cuja finalidade é dar ao povo a sua Torá e garantir que o povo possa viver feliz na nova terra, servindo ao Senhor seu Deus, praticando a justiça e vivendo como irmãos.

São exortações práticas que o líder dirige ao povo, inculcando em seu coração normas que visam demonstrar como Deus quer a vida e a plenitude do bem do povo. Ele não quer somente doar a terra, mas que o povo tenha vida e 
possa viver em liberdade, não repetindo a dureza da escravidão da qual Deus o tirou.

A felicidade e a liberdade, no entanto, dependem do acolhimento e da obediência com a qual Israel vai observar as palavras recebidas. Por isso, elas devem ser conhecidas, ensinadas e repetidas. A Torá envolverá todo o israelita; ele não viverá sem a sua palavra, pois será ela que o protegerá e garantirá a sua sobrevivência, mesmo quando tiver que viver fora da terra. No entanto, não basta a boa relação com o Senhor, a vida na nova terra deve ser em comunidade, na qual se pratica a justiça, sobretudo com relação à tríade social mais desprotegida (estrangeiros, órfão e viúvas).

Por sua vez, o termo hebraico DABAR significa tanto palavra ou discurso, como também acontecimento, coisa ou objeto, não é só o pensamento de uma vontade, mas a própria realidade que se designa, uma vez proferida a palavra, permanece viva e eficaz. Ela diz aquilo que as coisas ou os fatos são. Às vezes é o que foi feito e, em outras, um relato daquilo que foi feito.

Hoje a palavra está perdendo o valor, perde a força e a confiabilidade. Um exemplo disso é a enxurrada de fake news que inundam as redes sociais, desinformando as pessoas, num plano em que a mentira parece prevalecer à verdade. Chega-se ao absurdo de usar as palavras de Jesus "Conhecereis a verdade e a verdade vos libertará" (Jo 8,32) para justificar atitudes e projetos que vão contra a defesa da vida e das pessoas mais marginalizadas. Torna-se necessário recuperar o valor da palavra uma vez que, tanto para os judeus como para Jesus, as palavras têm poder, têm significado e representam muito além do que dizem.

\section{Referências}

AUSUBEL, N. Conhecimento Judaico II. Enciclopédia Judaica. Vol. 6. Rio de Janeiro: A. Koogan Editor, 1989.

BÍBLIA de Jerusalém. Introdução ao Livro do Deuteronômio. São Paulo: Paulus, 2002.

BLENKINSOPP, J. Deuteronômio. In: BROWN, R.; FITZMYER, J. A.; MURPHY, R. E. (Orgs.). Novo Comentário Bíblico São Jerônimo. Antigo Testamento. São Paulo: Academia Cristã / Paulus, 2007. 
BUNIM, I. M. A Ética do Sinai. Ensinamentos dos sábios do Talmud. São Paulo: Sefer,1998.

CRÜZEMANN, F. A Torá. Teologia e história social da lei do Antigo Testamento. Petrópolis: Vozes, 2002.

DI SANTE, C. Liturgia Judaica. Fontes, estrutura, orações e festas. São Paulo: Paulus, 2004.

EPHRAÏM. Jesus, Judeu praticante. São Paulo: Paulinas, 1998.

FRIZZO, A. C. Uma tríade social que qualifica o ato de conhecer a Deus. Pistis \& Praxis, Curitiba, v. 3, n. 1, p. 15-42, jan/jun. 2011.

KRAMER, P. Origem e legislação do Deuteronômio. Programa de uma sociedade sem empobrecidos e excluídos. São Paulo: Paulinas, 2006.

MAYES, A. D. H. Deuteronomy. The New Century Blible Commentary. London: Wm. B. Eerdmans Publ. Co. Grand Rapids. Marsharll, Morgan \& Scott Publ. Ltd., 1987.

MEYER, D. A vida fora da lei. É permitido salvar uma vida? São Paulo: Loyola, 2012.

OTTO, E. A Lei de Moisés. São Paulo: Loyola, 2011.

PAGANINI, S. Deuteronomio. Nuova versione, introduzione e commento. Milano: Paoline, 2011.

PAPOLA, G. Deuteronomio. Introduzione, traduzione e commento. Torino: Edizioni San Paolo, 2011.

SELTZER, R. M. Povo judeu, pensamento Judaico I. Enciclopédia Judaica. Vol. 1. Rio de Janeiro: A. Koogan Editor, 1990.

TORÁ, A LEI DE MOISÉS, Tradução de Ohel Yaacov. São Paulo: Sefer, 2001.

TRADUÇÃO Ecumênica da Bíblia (TEB). São Paulo: Loyola, 1994.

ZUMERKORN, D. Numerologia judaica e seus mistérios. Rio de Janeiro: Maayanot, 2005. 